\section{Análise da \\ Narrativa do Jogo Eletrônico: Estrutura, Imaginário e Mito em Super Mário Bros}

\section{Resumo}

Este artigo investiga a narrativa da franquia de jogos eletrônicos Super Mário Bros a partir dos trabalhos de Campbell (2005), que trata da função dos mitos e da jornada do herói; Durand (2001), que discorre sobre o imaginário como ferramenta para lidar com a angústia existencial (o tempo que passa e a morte que se aproxima inexoravelmente); Propp (1984), que executa extensa catalogação das estruturas narrativas existentes nos contos maravilhosos; e Todorov (2003), que se debruça sobre a questão da narrativa a partir da intriga e que investiga as variações possíveis à época para os romances do tipo policial. O corpus de trabalho são os títulos Super Mario Bros. (1985); Super Mario Bros 3 (1988); Super Mario World (1990); Super Mario 64 (1996) e Super Mario Galaxy (2006).

Palavras-chave: Super Mário Bros. Mito. Estruturas narrativas. Percurso do herói. Imaginário.

\section{Abstract}

This article investigate the narrative in the Super Mario Bros. videogame franchising, since the works of Campbell (2005), about the functions of the myths and the journey of the hero; Durand (2001), about the Imaginarium as a tool to deal with human existential distress (the time passing by, and the approaching death, inexorable); Propp (1984), who makes an extense cataloguing of the narrative structures in the fairy tales; and Todorov (2003), on the matter of the narrative from the intrigue, and investigates the variations possibles at his time in the detective stories. Our corpus includes the following titles: Super Mario Bros. (1985); Super Mario Bros. 3 (1988); Super Mario World (1990); Super Mario 64 (1996), and Super Mario Galaxy (2006).

Keywords: Super Mário Bros. Myth. Narrative structure. Journey of the hero. Imaginarium.
Prof. Me. Érico

Fernando de Oliveira

Mestre em Comunicação e

Semiótica pelo PEPGCOS/

PUC-SP.

E-mail:erico@pucpcaldas.br

Prof. Me. André

Campos de Carvalho

Mestre em Comunicação e Semiótica pelo PEPGCOS/ PUC-SP, professor, tradutor e estudioso do Imaginário materializado em HQs e animações.

E-mail: andre.campos. carvalho@gmail.com 


\section{Introdução}

A indústria dos jogos eletrônicos hoje supera as indústrias cinematográfica e fonográfica somados, com faturamento bruto acima de 91 bilhões de dólares em 2016 e previsão de ultrapassar a marca de 100 bilhões de dólares esse ano', um dos motivos pelos quais torna-se a cada dia um objeto de estudo mais relevante para o campo da comunicação, à medida que engendra novas formas de ser/estar no mundo hiperconectado, promove entretenimento e também instrução e, principalmente, encampa discursos ideológicos através de suas narrativas cada vez mais complexas. Exemplificamos o último caso com a bem-sucedida franquia Call of Duty ${ }^{2}$ cujos títulos apresentam narrativas sobre guerras, passadas, presentes e futuras, incluindo títulos que se referem ao terrorismo internacional (Modern Warfare I e II). Em suma, a "indústria dos videogames" é uma indústria hoje consolidada, lucrativa e com perspectivas de expansão, possuindo mecanismos próprios de legitimação. O mais importante deles talvez seja o Game Awards ${ }^{3}$, considerado o Oscar dos videogames e que tem categorias como Melhor direção de arte e Melhor narrativa. Pois é justamente a questão narrativa que nos interessa aqui, a partir dos trabalhos de Campbell (2005), que nos fala da função dos mitos e da jornada do herói; Durand (2001), que trata do Imaginário como ferramenta para lidar com a angústia existencial (o tempo que passa e a morte que se aproxima inexoravelmente); Propp (1984), que executa extensa catalogação das estruturas narrativas existentes nos contos maravilhosos; e Todorov (2003), que se debruça sobre a questão da narrativa à partir da intriga e que investiga as variações possíveis à época para os romances do tipo policial. Cientes de que temos de considerar que existem coerções de gênero, afinal esses autores tratavam de romances e aqui tratamos de jogos eletrônicos, que exigem, grosso modo, outro tipo de interação e outro ritmo narrativo, nos propusemos a investigar

http://bit.ly/2Iy52AU

2 Chamado do Dever seria uma tradução possível.

3 http://bit.ly/33f7QL7 que tipo de estrutura narrativa está presente na construção do jogo Super Mario Bros, sem dúvida alguma uma das franquias mais populares mundialmente. Salientamos que não se trata de um jogo épico, pomposo, como os RPGs multiplayers ${ }^{4}$ da atualidade. Trata-se inclusive de um jogo para todas as idades e de pouca complexidade operacional. Mario corre, pula e atinge adversários, coleta objetos mágicos que o auxiliam a percorrer sua jornada em busca de libertar a princesa, ora chamada de Princesa Peach, ora chamada de Princesa Toadstool (Cogumelo) da vilania de Bowser Koopa. Nessa breve descrição, apresentamos alguns elementos que evidenciam aquilo que Campbell (2005) denominou Jornada do Herói (Figura 1):

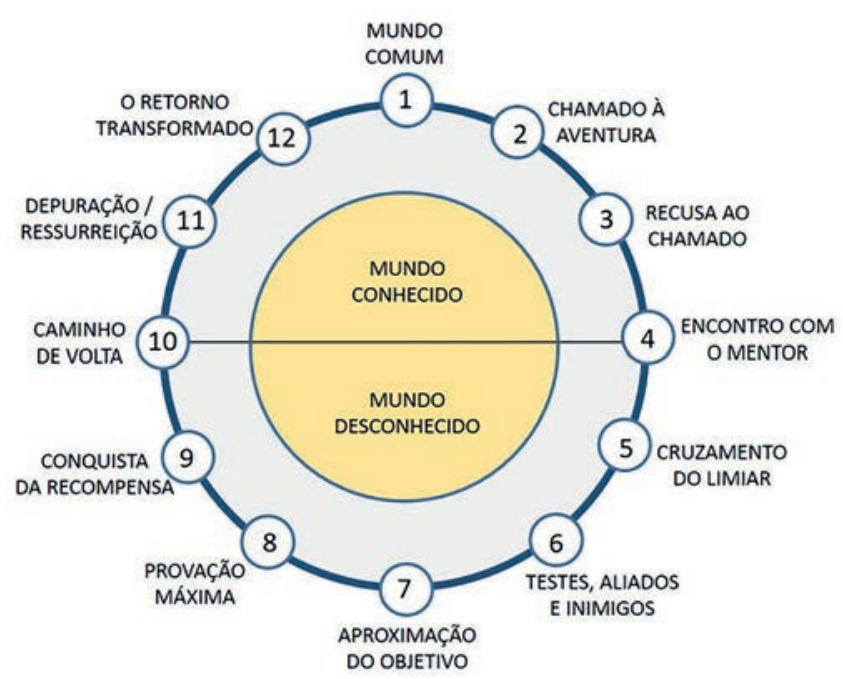

Figura 1 - A jornada do Herói descrita em 12 passos

Segundo Douglas Rushkoff: "uma crítica social sofisticada às vezes se esconde sob a superfície de gibis, jogos de videogame, entre outros, aparentemente idiotas" (CURTIS e ERION in ARP, 2007, p. 115). Pode-se ainda argumentar que, de acordo com Steinert "a distinção entre cultura erudita e cultura popular é ela mesma um fruto

4 Role Playing Game: jogos em que, como o próprio nome diz, é necessário desempenhar papéis. São compostos por diversos tipos de missões, que podem ser jogadas em grandes grupos ou individualmente. Essa modalidade cresceu exponencialmente nos últimos anos graças à tecnologia de transmissão de dados via banda larga, o que possibilita que jogadores do mundo todo atuem concomitantemente através da internet. 
da indústria cultural, e que o crítico deve estar sempre aberto a todas as práticas sociais significantes, independentemente de sua origem" (apud DURÃO, 2008, p. 41). Entendemos que, através do jogo, transmitem-se valores desejáveis para o bom funcionamento da sociedade, sendo assim, o jogo teria caráter pedagógico. Huizinga define o jogo como "uma atividade ou ocupação voluntária, exercida dentro de certos e determinados limites de tempo e de espaço, segundo regras livremente consentidas, mas absolutamente obrigatórias, dotado de um fim em si mesmo, acompanhado de um sentimento de tensão e de alegria e de uma consciência de ser diferente da 'vida quotidiana'" (2000, p. 24). Para esse autor, o jogo tem a importância congregatória, na medida em que, não raro, "as comunidades de jogadores geralmente tendem a tornar-se permanentes, mesmo depois de acabado o jogo" (idem, p. 12). Dito de outro modo, os jogos teriam a importante função de solidificar relações significativas, para além dos "laços frágeis" que Bauman (2005) denuncia no seu conhecido diagnóstico crítico da liquidez pós-moderna. O que Huizinga pretende é refutar a leitura de que o jogo seria uma atividade menor, supérflua, que não teria utilidade para indivíduos adultos. $O$ autor afirma que a atividade lúdica "dá satisfação a todo tipo de ideais comunitários" (2000, p.11). Ainda na trilha de Huizinga, suportamos sua percepção de que o jogo "se torna uma necessidade urgente na medida em que o prazer por ele provocado o transforma numa necessidade" (idem, p. 10). Em suma, o autor reflete que a atividade lúdica é uma função importante que está no cerne do desenvolvimento social da espécie humana.

\section{Super Mario Bros}

O encanador Mario (Figura 2) é a personagem principal de mais de 200 jogos, sendo que o primeiro jogo da série, Super Mario Bros, lançado pela empresa japonesa Nintendo em 1985 para consoles de 8 bits, é o jogo mais vendido de todos os tempos 5 . Mario tornou-se o carro-chefe da empresa e, via de regra, é o

5 Informação disponivel em http://bit.ly/33ghCfZ. jogo que acompanha o lançamento de cada console da empresa, marcando sempre uma fase de inovação tecnológica. De acordo com Segal (2011), a primeira aparição do super-herói criado pelo designer de jogos japonês Shigeru Miyamoto, aconteceu quatro anos antes, ainda chamado de Jumpman ${ }^{6}$ no jogo Donkey Kong (1981), lançado para diversas plataformas (no Brasil, ficou conhecido nos consoles da Atari)?.

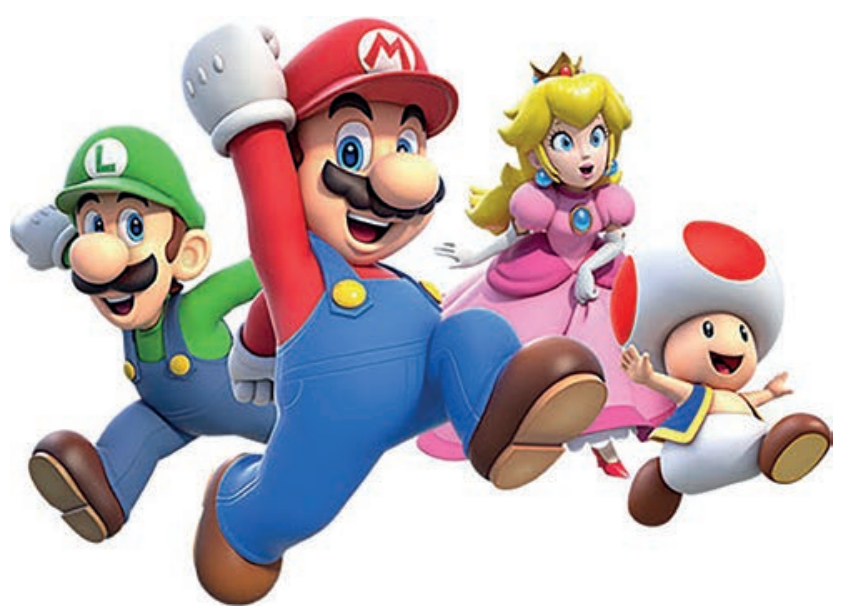

Figura 2 - Jogo Super Mario Bros

Segundo dados da Wikipedia, "como mascote da Nintendo, Mario é o personagem mais famoso da história dos videogames e a sua imagem está sempre associada a seus jogos. Até os dias de hoje, os jogos estrelados pelo personagem já venderam mais de 520 milhões de unidades no mundo inteiro". Com o passar do tempo, o universo Mario se ramificou para outras modalidades de jogos para além do consagrado side scrolling ${ }^{10}$ : RPGs, Esportes (Mario Kart, Mario Tênis, Mario Golf e Mario

6 Saltador (tradução nossa).

7 A legislação vigente à época proibia a importação de jogos eletrônicos. Os consoles e jogos só podiam ser fabricados no Brasil por empresas nacionais. Surgiram então diversos consoles que só foram comercializados aqui, como o Dactar II, fabricado pela Milmar, e o Dynavision, fabricado pela Dynacom, empresa integrante do grupo Gradiente. Sobre esse aspecto peculiar do mercado brasileiro de jogos eletrônicos, sugerimos a leitura de http://bit.ly/2B2u5rv.

8 https://en.wikipedia.org/wiki/Super_Mario

9 http://bit.ly/2IJj2YB

10 Side scrolling games são jogos em que a tela se desloca lateralmente. Foi a inovação que os videogames de segunda geração (8 bits) apresentaram, em detrimento dos jogos da primeira geração, cuja tela ficava fixa. 
Pinball Land, entre outros), que podem ser consideradas extensões marcárias" . No entanto, manteremos o foco da análise na série original, composta pelos títulos descritos a seguir (Tabela 1):

Tabela 1 - Corpus de análise

\begin{tabular}{|l|l|l|}
\hline \multicolumn{1}{|c|}{ Título } & \multicolumn{1}{|c|}{$\begin{array}{c}\text { Ano de } \\
\text { lançamento }\end{array}$} & \multicolumn{1}{c|}{ Console } \\
\hline Super Mario Bros & 1985 & NES $^{12}$ (8 bits) ${ }^{13}$ \\
\hline Super Mario Bros 314 & 1988 & NES (8 bits) \\
\hline Super Mario World & 1990 & $\begin{array}{l}\text { Super Nintendo } \\
\text { (16 bits) }\end{array}$ \\
\hline Super Mario 64 & 1996 & $\begin{array}{l}\text { Nintendo64 } \\
\text { (16 bits) }\end{array}$ \\
\hline Super Mario Galaxy & 2006 & $\begin{array}{l}\text { Nintendo Wii } \\
\text { (256 bits) }\end{array}$ \\
\hline
\end{tabular}

No que diz respeito ao estudo da narrativa, Todorov (2003, p.80) salienta que "a obra será sempre considerada como a manifestação de uma estrutura abstrata, da qual ela é apenas uma das realizações possíveis". O autor ressalta ainda que "o termo 'estrutura' tem pois aqui um sentido lógico, não espacial” (idem).

Vladimir Propp, em sua Morfologia do conto maravilhoso (1984), catalogou 100 contos de fadas russos, sintetizando-os em 31 funções narrativas básicas, que podem ou não aparecer num mesmo conto. Propp também aventou 7 personagens básicos: o herói (herói-buscador ou herói-vítima); mandante; malfeitor; doador; auxiliar (ser vivo ou objeto mágico); princesa e/ ou pai da princesa (rei) e falso-herói.

Os cinco jogos elencados possuem estrutura narrativa bastante similar, havendo algumas alterações: os três primeiros jogos são do tipo

11 Extensões marcárias, grosso modo, são ramificações da atividade primária de uma empresa/marca, na busca de ampliar sua participação em um segmento de mercado específico ou até mesmo de passar a participar de outros mercados.

12 Sigla para Nintendo Entertainment System

13 A quantidade de bits diz respeito à definição dos gráficos (resolução) e velocidade de processamento.

14 O jogo Super Mário Bros 2 possuiu uma contextualização diferente: nele é possível jogar com quatro personagens diferentes. Além de Mário e Luigi, é possível jogar também com Toad ou com a Princesa. side scrolling e os dois últimos são tridimensionais, com a personagem podendo se movimentar para todas as direções. Descrevendo rapidamente a narrativa do jogo: o Reino do Cogumelo (Mushroom Kingdom) é uma terra bucólica e que vive em perfeita harmonia. No dizer de Campbell, esse seria o primeiro passo da jornada do herói, um mundo comum. Até o dia em que o vilão Bowser Koopa, uma tartaruga-aligator que solta fogo pela boca, captura a princesa, retirando a harmonia desse mundo e efetuando um chamado a aventura ao herói (passo 2 da jornada do herói de Campbell). Para Propp o vilão é uma função narrativa: "Por função compreende-se o procedimento de um personagem, definido do ponto de vista de sua importância para o desenrolar da ação" (1984, p. 22). Essa é sempre a narrativa elementar de cada um dos cinco jogos.

A cada jogo são adicionados novos elementos e funcionalidades. Os jogos tornam-se mais extensos, com aumento no número de fases ou "mundos", como são chamados. Poderemos ainda utilizar a nomenclatura proposta por Propp: sequências. Para o autor, os contos de magia são divididos em sequências, que podem ocorrer de forma entrelaçada ou imediatamente após outra (Figura 3):

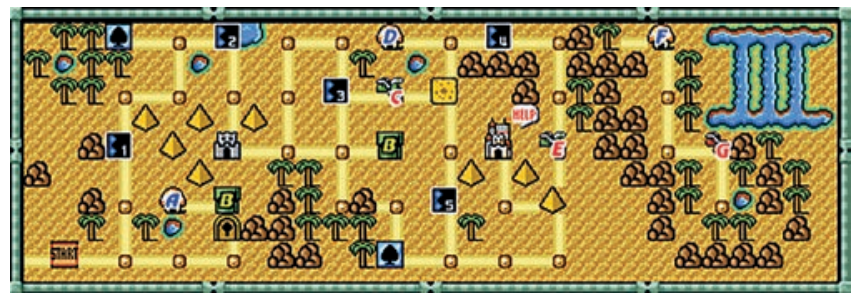

Figura 3 - Mapa de uma das sequências de Super Mario Bros 3

Nos jogos Super Mario World e Super Mario Galaxy observamos que existe a necessidade de acumular estrelas como condição sine qua non para desbloquear novas fases e missões. As estrelas seriam portanto, na definição de Propp, auxiliares, que podem ser um ser vivo ou objeto mágico cujas funções são: transportar o herói para onde ele precisa ir; reparar dano ou carência; salvar o herói quando o antagonista o 
persegue; solucionar as tarefas difíceis impostas ao herói; alterar a aparência do herói (dando-lhe ou devolvendo-lhe forma animal ou humana, presenteando novas roupas, eliminando um defeito físico). A narrativa de Super Mario Bros. está repleta de objetos mágicos, em todos os jogos (Figura 4):

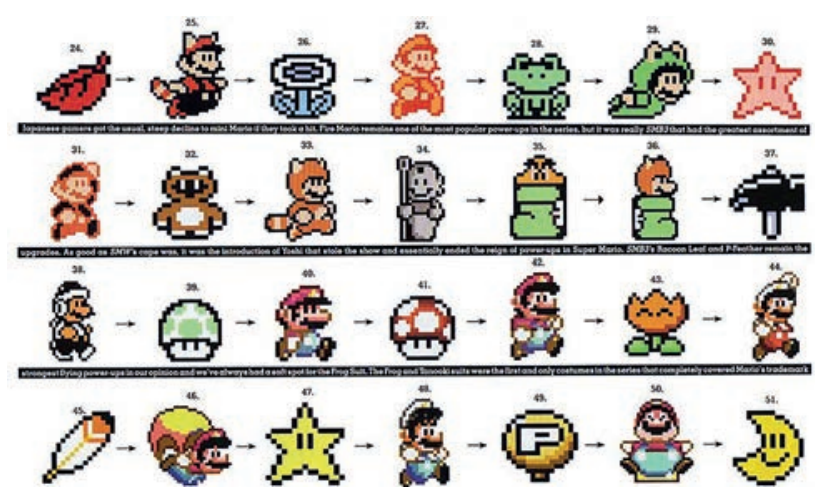

Figura 4 - Auxiliares nos jogos Super Mario Bros 3 e Super Mario World

Os objetos mágicos são adquiridos de três formas: a) durante as fases de jogo ao atingir elementos do cenário, especialmente os blocos coloridos com um ponto de interrogação; b) conquistados através de jogos de sorte inseridos nas fases e; c) Mario recebe o objeto mágico por intermédio de um doador. $\mathrm{O}$ doador, na definição de Propp é o personagem que submete o herói a provas e/ou transmite o objeto mágico. $O$ autor salienta que os personagens de um conto possuem esferas de ação, para qual propôs três modalidades distintas:

1. um personagem ocupa uma esfera de ação;

2. um personagem ocupa várias esferas de ação (p.ex:: o animal agradecido pode ser doador e mais tarde auxiliar; o pai que envia o herói em busca de algo e lhe dá um conselho ou objeto mágico atua como mandante e doador);

3. vários personagens alternam-se em uma esfera de ação (p. ex.: a cada etapa o herói é submetido a provas por um doador diferente).

No caso das narrativas do jogo Super Mario Bros 3, a princesa é a doadora. Ao final de cada sequência em que Mario derrota um dos sicários do vilão principal, Bowser Koopa, ele recebe da princesa uma carta com uma mensagem e um objeto mágico anexado (Figura 5):

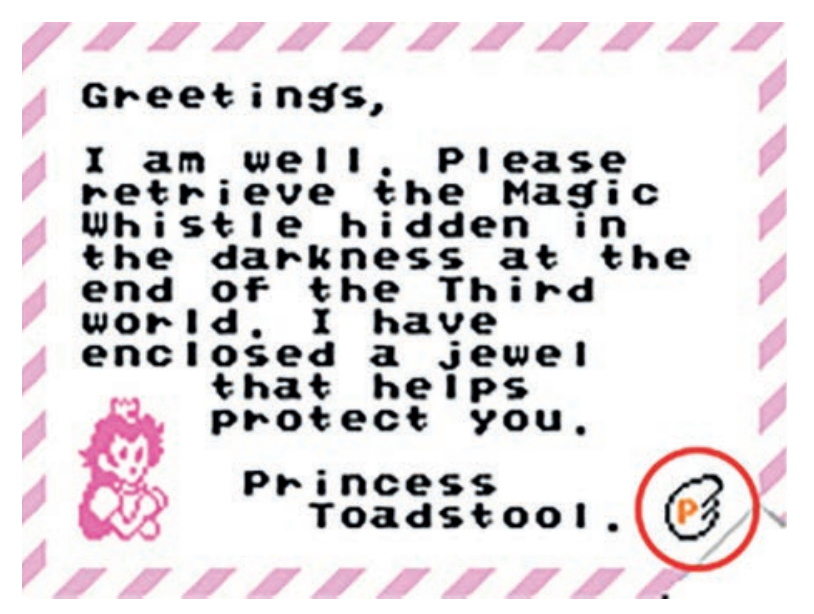

Figura 5 - Doação do objeto mágico no jogo Super Mario Bros 3

Ao final de todas as sequências, Mario finalmente enfrentará o grande vilão, Bowser Koopa. Um detalhe que nos chama atenção é o fato de que ele não pode tocar no vilão e por isso sempre tem que fazer uso de algum objeto, por vezes fornecido pelo próprio koopa, no intuito de feri-lo. Em outros casos, Mario precisa usar a astúcia para driblar o vilão (p. Ex.: em Super Mario Bros. Ele tem de passar por cima ou por baixo do vilão, que está soltando bolas de fogo, e acionar uma alavanca para derrubá-lo; em Super Mario 64, ele precisa agarrar o Koopa pela cauda e lança-lo na direção de bolas de espinho) (Figura 6):

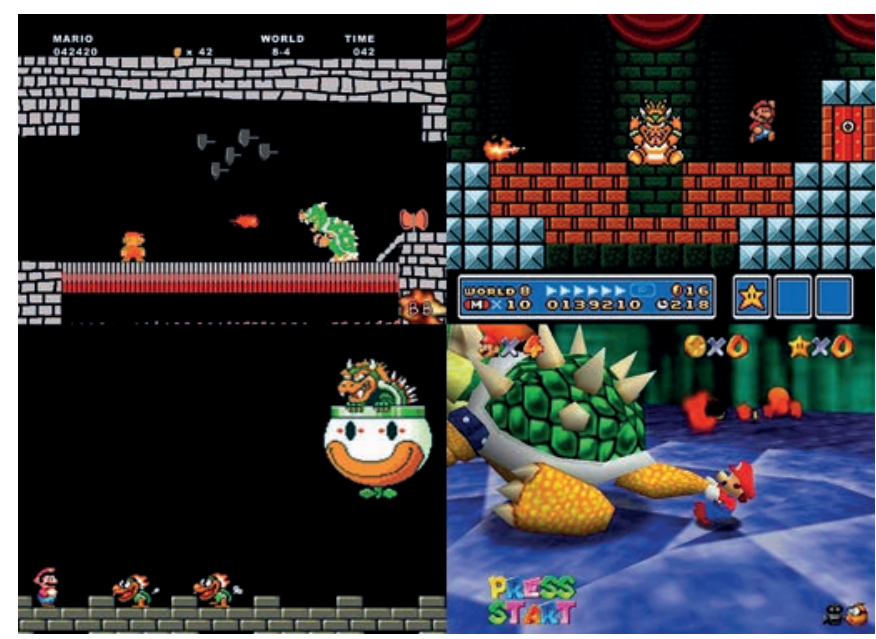

Figura 6 - Confronto final entre Mario e Bowser em Super Mario Bros. Super Mario Bros 3, Super Mario 64 e Super Mario World (sentido horário) 


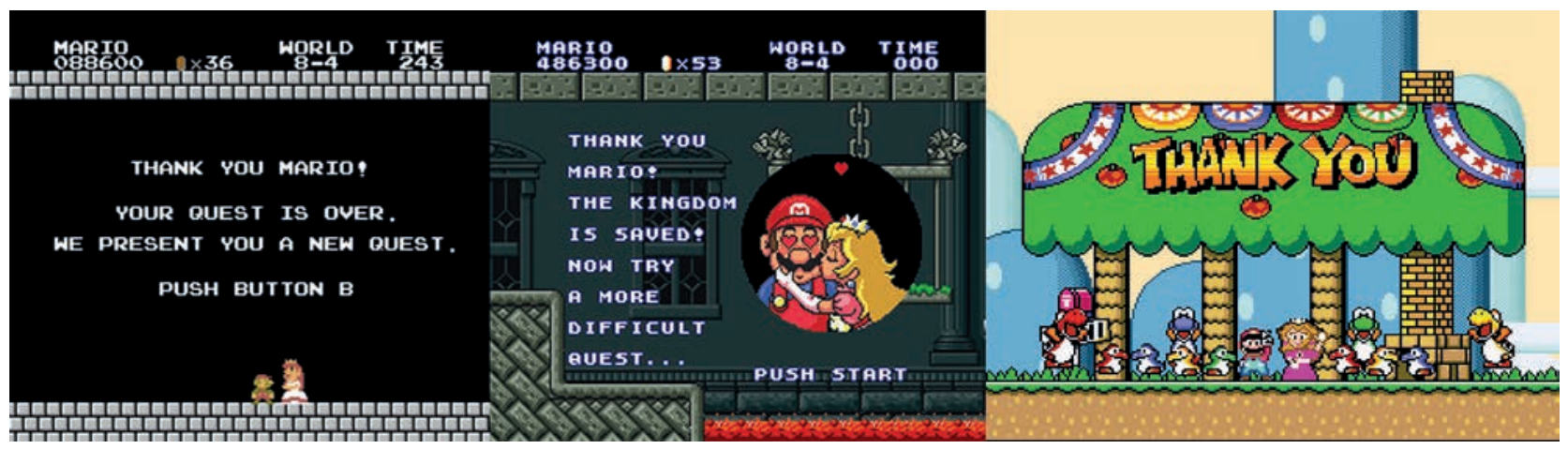

Figura 7 - Mario salva a princesa e a paz volta a reinar (mas por pouco tempo)

Uma vez que Bowser é derrotado, Mario liberta a princesa, recebe sua recompensa e a paz no reino é reestabelecida (Figura 7), efetuando-se assim a última etapa da jornada do herói de Campbell, com a ressalva de que o autor prevê um herói transformado, o que não cremos ser o que ocorre com Mario.

Nesse sentido, Mario pode-ser considerado um herói absurdo, conforme descrito por Camus no Mito de Sísifo (2010). Mario salva a princesa somente para tornar a salvá-la na próxima edição do jogo, repetindo as mesmas rotinas da versão anterior, assim como Sísifo fora condenado a rolar uma imensa pedra montanha acima só para vê-la descer.

Gilbert Durand, em sua clássica tese de doutoramento As estruturas antropológicas do Imaginário (2001), descreve o mito como um "sistema dinâmico que, sob o impulso de um esquema ${ }^{15}$, tende a compor-se em narrativa" (2001, pp. 62-63). Como já observamos acima, com Campbell, o mito hoje se mantém ativo nos meios de comunicação, cinema, histórias em quadrinhos, séries, videogames, e graças aos aparatos audiovisuais onipresentes em nossa era as narrativas se expressam em imagens. Ora, narrativas que se expressam em imagens são o próprio campo de estudos do Imaginário. Durand entende o Imaginário como um modo

15 Esquema (schème), aqui, como descrito pelo próprio antropólogo das imagens: "uma generalização dinâmica e afetiva da imagem (...) ao que Bachelard chama 'símbolo motor' (...), o esqueleto dinâmico, o esboço funcional da imaginação" (DURAND, 2001, p. 60). de organizar o real, um recurso para lidar com a angústia existencial que marca o ser humano: o tempo passa inevitavelmente e todos inexoravelmente passaremos pela experiência da morte.

Segundo Ferreira-Santos e Almeida (2012, pp. 19-29), para lidar com essa angústia existencial, o humano desenvolve três estratégias básicas, a que Durand chamou estruturas: uma estrutura heroica, que usa de antíteses para separar o humano do terrificante, isto é, imagens que simbolizam a ascensão, a luz e a separação, e que se contrapõem às imagens que simbolizam a queda, a escuridão e o devoramento (o trincar com dentes); uma estrutura mística, em que as imagens terrificantes são eufemizadas através da antífrase, isto é, a queda abrupta eufemiza-se em descida lenta, a escuridão assustadora em noite divina, o devoramento que destrói com dentes em engolimento suave; e uma estrutura dramática, em que o tempo é domesticado, permite tanto uma repetição que nos leva do tempo profano (esse que mata) ao tempo sagrado (aquele que cria), e "a noite não passa de propedêutica necessária do dia, promessa indubitável da aurora" (DURAND, 2001, p. 198), quanto a uma transformação incessante, fecundidade e perenidade do ancestral.

Nos parece importante desencorajar a classificação estanque das imagens. $O$ verbo, ou ainda, a função da imagem é mais importante que a representação. Isso garante a dinâmica do sistema proposto por Durand. Então, a estrutura heroica se caracteriza mais por verbos 
como "separar" e "subir"; a estrutura mística por "descer", "misturar", "guardar"; a estrutura dramática por "criar" e "renovar". Da mesma forma, crer na pureza de uma imagem também não é recomendável. Elementos próprios das três estruturas podem aparecer em qualquer representação, seja ela material (como um videogame) ou imaterial (como um hábito).

Super Mario Bros, em todas as versões presentes em nosso corpus, pode ser entendido como uma representação bastante heroica. Há um reino de harmonia, e há um vilão desarmônico, o esquema de separação é bastante claro: o vilão sai de seu subterrâneo para raptar a princesa, símbolo da pureza e harmonia, e um herói é convocado para derrotar o vilão, manda-lo de volta ao submundo (a vitória de Mario sobre Bowser Koopa se dá sempre pela queda). O vilão é um gigante quando comparado ao herói, um monstro guerreiro armado com carapaça, espinhos e uma bocarra contra um mero encanador de suspensórios e boina: " A hipérbole negativa não passa de pretexto para a antítese" (idem, p. 123). Considerar a vitória de Mario sobre Bowser como a simples afiguração dessa estrutura é bastante objetivo e claro. Vale notar que estão presentes elementos próprios da estrutura mística, como a inversão na vitória improvável do anão sobre o gigante (assim como o mito bíblico de Davi e Golias) e o fato de que Mario é um encanador (portanto um ser "engolido" pelos tubos, guardado nas entranhas daquele mundo), assim como nos monstros eufêmicos a que o jogo recorre: os dentes de Bowser Koopa são arredondados e a morte de Mario, quando se perde no jogo, implica um susto mais que uma destruição. Tudo no jogo é de extrema fofice.

Mas há um elemento que queremos colocar em relevo: se acima ressaltamos o absurdo da tarefa de Mario comparando-a ao Sísifo de Camus, isso nos leva ao esquema dramático das imagens conforme a descrição de Durand (2001, p. 197). Assim como o mito de Sísifo é uma simbólica cíclica, que consola o humano do tempo que passa pela promessa de uma repetição infinita, da mesma maneira Mario só salva a Princesa para ter que salvá-la de novo, tanto na sequência cronológica dos jogos analisados quanto no simples fato de podermos reiniciar o jogo logo depois de termina-lo. Paralelamente, observam-se também imagens de progresso, seja na expansão do Reino dos Cogumelos, que a cada versão fica maior e mais complexo, seja nas transformações técnicas, como as mudanças na qualidade gráfica de cada versão ou a mudança de um modelo side scrolling para um tridimensional.

\section{Considerações Finais}

Analisamos a série de jogos Super Mario Bros com o intuito de investigar a constituição de suas estruturas narrativas. Partimos dos estudos de Campbell (2005), Propp (1984) e Todorov (2003) e, como pudemos demonstrar em nossa análise, encontramos diversos elementos que remetem às catalogações descritas pelos autores citados. Entendemos que o jogo é muito mais que mero entretenimento destinado às massas. Mario nos convida a aceitar um chamado à aventura de estar vivo, desafiar as adversidades e compreender o valor da colaboração e da possibilidade de viver uma vida virtuosa, mesmo sendo um sujeito aparentemente comum. E ainda, acompanhando a visão de Durand (2001), nota-se a organização das imagens em uma narrativa que pode ser observada tanto em seu caráter cíclico, que nos consola do tempo que passa pela eterna repetição do mito de "salvar a princesa" e pela continuidade da narrativa, ao mesmo tempo que sugere um progresso, pela evolução de personagens e pela renovação de elementos, sejam símbolos renovados, sejam aparatos técnicos melhorados.

\section{Referências}

ARP, R. South Park and philosophy: you know, I learned something today.USA: Blackwell, 2007.

BAUMAN, Z. Vida Líquida. Rio de Janeiro: Jorge Zahar, 2005.

CAMPBELL, J. O poder do mito. São Paulo: Pallas Athena, 2005. 
CAMUS, A. O mito de Sísifo. Rio de Janeiro: Record, 2010.

DANTAS, T. "A história do Mario"; Brasil Escola. Disponível em <http://brasilescola.uol.com.br/ curiosidades/a-historia-mario.htm>. Acesso em 24 de julho de 2017.

DURAND, G. As estruturas antropológicas do imaginário: introdução à arquetipologia geral (Trad. Hélder Coutinho), $2^{a}$ ed. São Paulo: Martins Fontes, 2001.

DURÃO, F. A. et al (org). A Indústria Cultural hoje. São Paulo: Boitempo, 2008.

FERREIRA, M. "Indústria de games supera o faturamento de Hollywood" <http://www.webnoticias.fic.ufg.br/n/68881-industria-de-games -supera-o-faturamento-de-hollywood>. Acesso em 21 jul 2017.

FERREIRA-SANTOS, M.; ALMEIDA, R. de. Aproximações ao imaginário: Bússola de investigação poética. São Paulo: Képos, 2012.

HUIZINGA. J. Homo Ludens. São Paulo: Perspectiva, 2000

PROPP, V. Morfologia do conto maravilhoso. Rio de Janeiro: Forense universitária, 1984.

SEGAL, S H. Geek Wisdom. Philadelphia: Quirk Books, 2011.

WUNENBURGER, Jean-Jacques. O imaginário (trad. Maria Stela Gonçalves). São Paulo: Loyola, 2007. 